Alma Mater Studiorum - Università di Bologna DEPARTMENT OF ECONOMICS

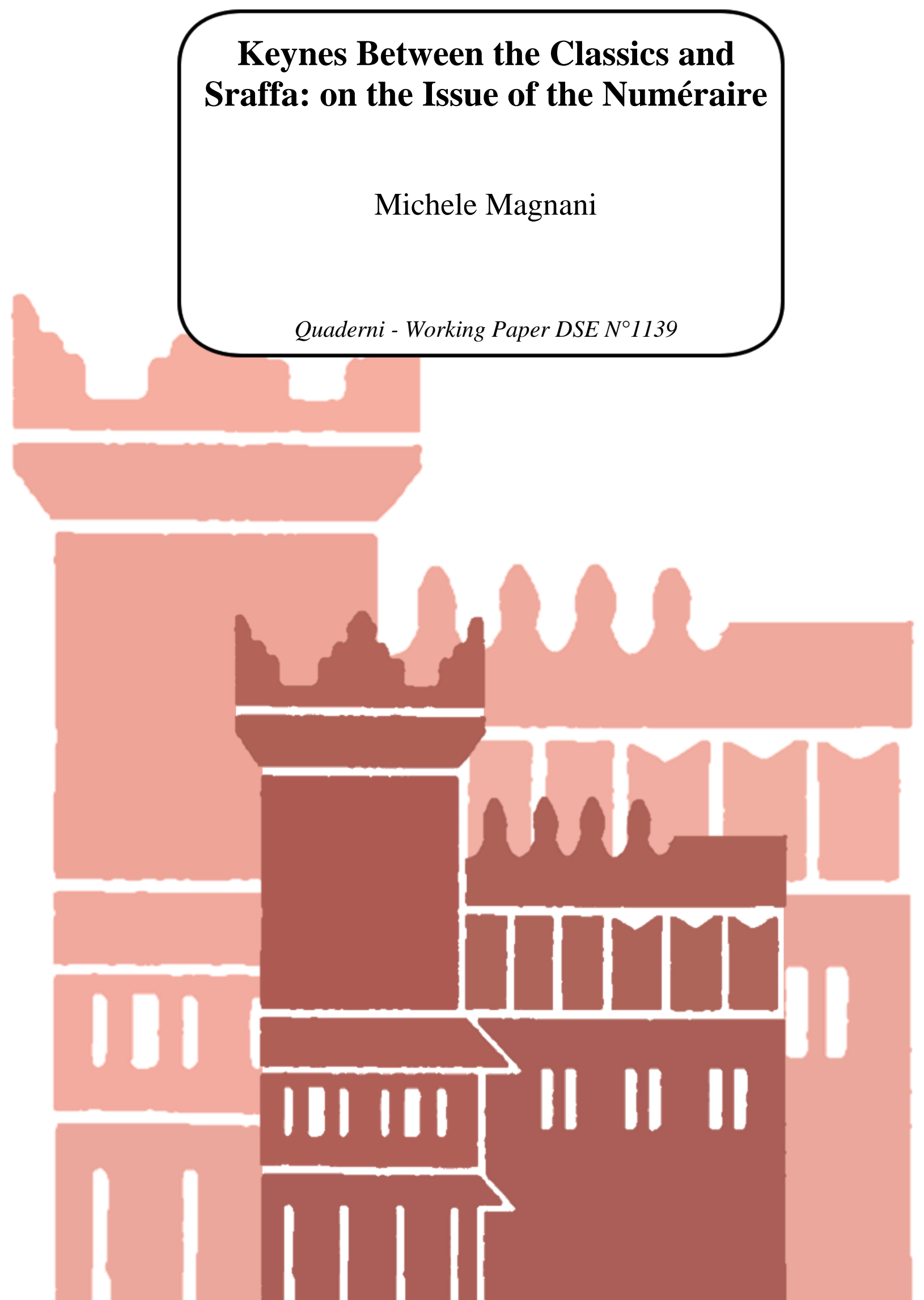




\title{
KEYNES BETWEEN THE CLASSICS AND SRAFFA: ON THE ISSUE OF THE NUMÉRAIRE
}

\section{Michele MAgnAni*}

July 2019

\begin{abstract}
The paper sketches a coherent history of the choice of the measure standard from Adam Smith's Wealth of Nations to Sraffa's Production of Commodities. As neither the Smithian labour commanded unit nor the Ricardian-Marxian labour embodied one provide a general solution to the dilemma concerning the finding of an invariable standard, the author shows the shortcomings of both methods in an analytically rigorous way. Several years later, the largely unacknowledged fourth chapter of the General Theory once again tackles the matter of measuring aggregate values adopting a net approach and introducing an ad hoc unit. Concerned by the inherent difficulties of the operation, Keynes starts from an harsh criticism towards Pigou's notion of national dividend to end up asking himself a number of questions that makes him partially lean towards the later Sraffian approach as presented in Production of Commodities, though his stance is not fully compliant either with the premises or the aims of Piero Sraffa's theoretical framework. In the final part, a general solution based on net labour productivity is considered.
\end{abstract}

Keywords: History of Economic Thought; Classical Political Economy; Post-Keynesian Economics; Choice of Units; Theory of Value.

JEL Classification: B12; B14; B24; B51.

\footnotetext{
* Corresponding author: graduate research and teaching assistant, Department of Economics, Università di Bologna, Strada Maggiore 45, 40125 Bologna, Italy; michele.magnani9@unibo.it
} 


\section{NON TECHNICAL SUMMARY}

This working paper provides a detailed excursus of the different stances that the broadly defined Classical School has taken towards the choice of the numéraire in analytical models. Although the need for assessing economic magnitudes has arguably been a primary concern for scholars since the birth of economics as a stand-alone discipline, only few economic thought historians have made efforts to understand the evolution of the subject. Starting from the actual texts of XIX and XX century authors, linear algebra is employed to reduce heterogeneous theoretical structures to a common ground and propose a normalisation.

The main aim of this contribution is to argue in favour of the existence of an effective fil rouge encompassing the intellectual works of the likes of Smith, Ricardo and Sraffa when it comes to the problem of the unit of measure. What is more, Keynes is included in this tradition too due to some hints scattered in his magnus opus, which makes him close to his Cambridge colleague Piero Sraffa, partially anticipating some features of the latter's solution. Each scholar's position is presented in a chronological order so that a coherent evolution pattern could emerge; faults and shortcomings are highlighted in order to display the main critical points of this tradition as well as the successive attempts to overcome them building on earlier failures.

In the conclusion, an alleged extension of the Sraffian solution is presented, while its theoretical foundations and potential as an empirical tool are evaluated. 


\section{Introduction $^{1}$}

The measure of wealth is one of the greatest challenges economists has been accustomed to face since the birth of their discipline. In a sense, it could be even said that modern economic thought first rose to inquire into this very problem with William Petty's Political Arithmetick (1690). His work, deeply rooted in a world that had yet to know the great changes of industrialisation, made an attempt to evaluate riches, levels of production and all sort of economic quantities in terms of two units, namely land and labourers' subsistence. Although he sought to assess the dimension of the surplus, the fundamental object of study of economic theory until the marginal revolution, in purely material terms, he still needed to aggregate the goods which compose it and thus made use of both his units, moving from one to the other having recourse to an approximate equivalence based on the supposition that the wage of the labourers is materially identical to the product of the land. After Petty, this notion of cost as the "loaf of bread" (Kurz, 2006; Perri, 2010), would also be adopted by the French Physiocratic school, whose analysis of agricultural and manufacture activities under the Ancien Régime largely influenced the formation of Adam Smith's economic thought, which is the first author whose argument shall be carefully examined in the following of this work.

Seccareccia (1982) maintains that there exists a link between the economists of the late XVIII and early XIX centuries on the one hand and Keynes and Sraffa on the other, claiming that the choice of the standard has been a central issue in the analysis of each of these scholars. Thus, albeit the 'centrality' of the question in the Keynesian theory is rather debatable, it does not come as a surprise that the analytical representations of the theories

\footnotetext{
${ }^{1}$ In this work I try to further develop some ideas that I first came in touch with during the writing of my Master Thesis; I am greatly thankful for the encouragement and the guidance of prof. Giorgio Gattei and prof. Giancarlo Gozzi, whose efforts ultimately granted me a thorough understanding of the theoretical structure of Classical Political Economy. I will always cherish their lessons and suggestions. I am also willing to thank prof. Raimondello Orsini for his constant intellectual challenge, as well as prof. Roberto Scazzieri and prof. Massimo Amato, from Bocconi, for having passed me at least a share of their perspicacity when it comes to historical issues. Needless to say, all faults and errors are mine.
} 
exposed below differ very little from each other, showing indeed a gradual evolution towards a complete generalisation of the doctrine concerning the measure standard. The first three parts discuss the contribution of Smith, Ricardo and Marx with their use of the labour theory of value. The chapter on Keynes outlines the intellectual background from which he derives the interest for the issue and the implications of his solution. The last two sections are devoted to Piero Sraffa's contribution and tries to highlight its affinity with those of the Classics and Keynes respectively.

One of the aims of this paper is to argue in favour of the existence of an intellectual fil rouge that links the Classics to Sraffa through the work of Keynes. In doing so, it will also try to back the position of those who wish for a potential synthesis of the current Post-Keynesian and Neo-Ricardian schools, however many diversities persist between them, in the name of a common heritage (Pasinetti, 2007). 


\section{Smith's «command over labour»}

In the second half of the XVIII century, the debate concerning the unit of measure was opened by Adam Smith's Wealth of Nations, arguably the first masterpiece in the history of economic analysis. In the fifth chapter of his magnum opus Smith affirms that the real price of each and every commodity is the 'toil and trouble' expended to acquire it. Since he is willing to limit the validity of a labour embodied theory of value to the "early and rude state of society' prior to the accumulation of capital stock, whenever, as in modern economies, private ownership of the means of production prevails it cannot be found any simple rule linking the quantity of labour (directly and indirectly) employed in producing a commodity and its price (Smith, [1776], ch. V). As a consequence, in such a state of things the goods are exchanged according to the labour they can purchase at the prevailing wage rate, that is to say the value of a commodity can only be traced back to the labour it commands. Relative prices are then calculated as ratios between respective purchasing power on labour (ibid., ch. VI).

Let $\mathbf{p}=\left(p_{i}\right)$ be the vector of relative prices for commodities $i=1, \ldots, n, r$ the profit rate, $\omega$ the relative wage rate, $(\mathbf{A}, l)$ the employed method of production. ${ }^{2}$ The economic system can be represented as follows: $:^{3}$

$$
\mathbf{p}=(1+r) \mathbf{A p}+\omega l
$$

System (1.1) captures the structure of a competitive capitalist economy producing $n$ commodities. Prices are determined on account of a free competition condition, which makes $r$ as well as $\omega$ uniform across the sectors. Fixing a labour commanded unit of measure implies setting:

\footnotetext{
${ }^{2}$ We assume the square $(n \times n)$ matrix $\mathbf{A}$ to be indecomposable and productive.

${ }^{3}$ Note that here and in what follows we hypothesise the salary to be paid at the end of the period contrary to what classical economists maintained, so that the workers' means of subsistence are not part of the advanced capital matrix A. We also assume that no rent is paid in the system.
} 


$$
\omega=1
$$

Hence, the system becomes:

$$
\widehat{\mathbf{p}}=(1+r) \mathbf{A} \widehat{\mathbf{p}}+l
$$

The relative prices of vector $\widehat{\mathbf{p}}$ are therefore expressed in terms of the uniform wage, i.e. labour commanded is the measure of commodities' exchange value.

The labour commanded position on the unit of measure debate, which would be notably defended by Robert Malthus among the posterity of Smith, allows for a correct representation of the competitive mechanism that operates in a capitalist economy, ensuring that the condition for a uniform rate of profit across the sectors is satisfied. On the other hand, a labour commanded standard is not invariant with respect to shifts in income distribution. In fact, system (1.3) can be rearranged to obtain:

$$
\widehat{\mathbf{p}}=[\mathbf{I}-(1+r) \mathbf{A}]^{-\mathbf{1}} l
$$

where it is immediately shown that vector $\widehat{\mathbf{p}}$ of relative prices determined in terms of labour commanded depends on the rate of profit. Defining the value of the aggregate profit and the value of the advanced means of production ${ }^{4}$ respectively as:

$$
\begin{aligned}
& \Pi=\mathbf{y} \widehat{\mathbf{p}}(r)-L \\
& K=\mathbf{q A} \widehat{\mathbf{p}}(r)
\end{aligned}
$$

Where

$$
\mathbf{y}=\mathbf{q}(\mathbf{I}-\mathbf{A})
$$

\footnotetext{
${ }^{4}$ Both in terms of labour commanded, as the two aggregate quantities could be treated in physical terms only in the restrictive cases of equal material composition or, even more unrealistic, production of a single good; in the general case, a valuation at prices, which in this paragraph are expressed in labour commanded, is needed in order to make the quantities comparable
} 
is the net product of the economy, and

$$
L=\mathbf{q} l
$$

is the aggregate labour expended in production, equal to the total amount of wages since in this context we put $\omega=1$.

It follows that the rate of profit is obtained as:

$$
r=\frac{\Pi}{K}=\frac{\mathbf{y} \widehat{\mathbf{p}}(r)-L}{\mathbf{q} \mathbf{A} \widehat{\mathbf{p}}(r)}
$$

which highlights the implied logical issue of this unit of measure, that of a circular reasoning - in order to determine the profit-rate we need to know relative prices in advance while at the same time these exchange values depend on the level of the rate of profit. ${ }^{5}$

Smith's unit of measure correctly depicts the competitive dynamics of a modern economy but leads to a misrepresentation in the occurrence of changes in the distributional variables as it involves a circular reasoning. The seek for a measure that would be invariant with respect to shifts in distribution was the problem that bothered Ricardo till his last days, a riddle he sought to solve putting forward a labour embodied theory of value.

\footnotetext{
${ }^{5}$ Actually, it is just with a labour embodied standard, which will be examined in the following chapter, that prices can be ascertained before the rate of profit is assessed. On the other hand, the modern Sraffian solution avoids the circular reasoning allowing for a simultaneous determination of the variables.
} 


\section{Ricardo's «embodied labour»}

According to David Ricardo, the determination of the laws which regulate income distribution is "the principal problem in Political Economy" (Ricardo, [1821]). Solving this problem means explaining the causal relationships between the three distribution variables: rent, wage and rate of profit. While Ricardo can put aside rent thanks to his 'differential theory of rent' which demonstrate that it does not influence the determination of production prices, and while wages are fixed at the subsistence level on account of the Malthusian principle, the rate of profit is calculated as the ratio between aggregate profits and advanced capital. The two quantities are not materially homogeneous and need to be made so. $\mathrm{He}$ initially reaches this goal (or rather, dodge the question) with his corn model, focusing on the agricultural sector whose output and capital are supposed to be represented by the same commodity (Sraffa, 1951).

On account of several critiques by his friends and colleagues, Ricardo rejects his earlier elaboration to search for a standard that would not be influenced by changes in distribution and technological patterns, having recourse to the labour theory of value. Eventually, an invariant unit would enable him to successfully criticise the so-called 'additive theory' set forth by Smith, proving that a rise in wages does not necessarily lead to an equal increase in prices due to the impact on income distribution.

As stated in the Principles of Political Economy ([1821]), the price of each commodity should be proportional to the difficulty of production in terms of hours of human effort, just like Adam Smith maintained. Differently to Smith, however, Ricardo considers the gravitation mechanism of prices toward labour values to be at work in modern industrial societies as well. The 'prince of economics' goes on to say that "it is the comparative quantity 
of commodities which labour will produce, that determines their present or past relative value, and not the comparative quantities of commodities, which are given to the labourer in exchange for his labour" (Ricardo, [1817], p. 11).

Algebraically, this condition is expressed by:

$$
\mathbf{p}=\alpha \lambda \text { with } \alpha>0^{6}
$$

where

$$
\lambda=\mathbf{A} \lambda+l=[\mathbf{I}-\mathbf{A}]^{-1} l
$$

is the vector of commodities' labour embodiment, which in turn is positive if the economy is viable. $^{7}$

This last equality gives expression to the most restrictive condition a labour embodied approach can lead us to, that is a perfect correspondence between prices and labour values for each and every commodity. This equality shall be reflected by the equation for the numéraire.

In order to get to it, each side of equation (2.1) can be multiplied by the same composite-commodity non-negative vector $\mathbf{x}$, that is:

$$
\mathbf{x p}=\mathbf{x} \lambda
$$

Vector $\mathbf{x}$ displays no peculiarity whatsoever; (2.2) just shows that, as long as (2.1) has validity, any arbitrary chosen bundle of commodities (or even a single commodity, potentially 'corn': in this case the elements of the vector will all be zero but one) is numerically the same evaluated at prices and at labour values.

Now, $\mathbf{z}$ can be defined as a vector representing a composite commodity directly and indirectly requiring exactly one unit of labour for its production:

\footnotetext{
${ }^{6}$ In general, we should express the proportionality between prices and labour values through the parameter $\alpha>0$, that is $\mathbf{p}=\alpha \lambda$. In the following, $\alpha$ is made equal to 1 for the sake of simplicity.

${ }^{7}$ In other words, the 'Leontief inverse' has positive elements when the Hawkins-Simon condition is fulfilled.
} 


$$
\mathbf{z}=\frac{\mathbf{x}}{\mathbf{x} \lambda}
$$

Equation (2.3) algebraically defines labour embodied as the standard of value. Exchange values can then be ascertained as ratios between the prices of the $n-1$ goods and that of the numéraire (normalised to 1), that is between the respective quantities of labour (directly and indirectly) required in their production.

$$
\begin{aligned}
& \mathbf{p}=(1+r) \mathbf{A p}+\omega l \\
& \mathbf{z p}=1
\end{aligned}
$$

This latter system is formally equivalent to that of Smith except for the choice of a unit of measure expressing a quantity of embodied labour. Prices here directly mirrors labour values rather than being an expression of purchase power over labour.

As it can be seen, with the adoption of numéraire (2.5) the unit of count is not influenced by the distribution of income and therefore it is possible to recognise and isolate price variations induced by changes in distribution patterns. Thus, a labour embodied theory of value seems to overcome the obstacle the Smithian one leaves in place. Unfortunately it is not so, because such a standard does not generally respect the requirement for a uniform rate of profit throughout the economy as prices adjust themselves under the competitive push for the equalization of $r$, while labour values are mere displays of technical necessities. The case in which the price of each single good is equal to its labour embodiment is that of uniform proportion between direct and indirect labour for any said good.

Let's find the condition under which $\mathbf{p}=\lambda$ is true. From the price equation we get:

$$
\lambda=(1+r) \mathbf{A} \lambda+\omega l
$$

that is 


$$
(\mathbf{I}-\mathbf{A}) \lambda=r \mathbf{A} \lambda+\omega l
$$

Since $\lambda=\mathbf{A} \lambda+l$, we can simplify the latter to

$$
\lambda=\frac{(1+r)-\omega}{r} l^{8}
$$

which is the condition for an equal direct/indirect labour ratio in each industry.

This cross-sectoral hypothesis, which Ricardo labels 'uniform capital intensity' (and that Marx, later on, would identify as 'uniform organic composition of capital'), is - needless to say - rather implausible in real world situations, such that it stands as a simple curiosum apt to show the correctness of the classical theory of value under restrictive conditions.

Therefore, besides the uniform capital intensity special case, the Ricardian labour embodied theory of value coherently represents the working of a capitalist economy only in the trivial case in which labour is the sole productive factor and the society finds itself in an "early and rude state" à la Smith. Ricardo acknowledges these shortcomings and nevertheless maintains that his labour theory of value should be regarded as a trustworthy proxy for relative prices, whose divergence from labour values would never exceed ' 6 or 7 per cent' - a claim notoriously lampooned by Stigler's paper on the "93\% labour theory of value" (Stigler, 1958). The ambiguity lies in the fact that the grade of approximation, i.e. the spread between value and price, does not vary with $r$ in a systematic way: in the end, it cannot be ascertained whether the shifts are due to variations in the value of the numéraire or of the commodity object of measure. Thus, Ricardo states, we have to find "some invariable standard measure of value, which should itself be subject to none of the fluctuations to which other commodities are exposed" (Ricardo, [1821], pp. 43-4). With no such 'average commodity' to

\footnotetext{
${ }^{8}$ Since $l$ is positive, $\lambda$ is the highest real eigenvalue of matrix $\mathbf{A}$.
} 
be found, we are unable to treat together price and distribution theories within the classical approach in a coherent manner. ${ }^{9}$

\section{Marx and the aggregate invariance postulate}

Embodied labour, although ill-defined as a measure to compute value in exchange (the relative prices structure of the economy), serves also another purpose as it reveals the substance, the 'fundamental essence' of commodities value, that is to say the quantity of human effort expended upon their production. As a consequence, the problem of finding a suitable unit of measure merges with that of determining absolute values, i.e. the real social costs sustained for the reproduction of the economy independently of the specific features of the system. ${ }^{10}$ This stance, broadly defended by the Classical Political Economy, is particularly explicated by Marx ([1867]). According to the German thinker, creation of value happens at the stage of production by means of direct labour and such value is left unaltered through exchange while prices limit themselves to redistribute it. This, however, does not mean that prices and values completely overlap: rather, prices are 'transformed values' and thanks to this subtle distinction the Marxian solution allows the former to generally diverge from the latter. Anyway, the link between the quantities still holds as prices are the phenomenal manifestation of a concealed essence that capitalist competition distorts and veils.

\footnotetext{
${ }^{9}$ As it is widely known, Sraffa (1960) overcomes the Ricardian impasse concerning the invariable standard with the auxiliary device of the 'Standard commodity'.

${ }^{10}$ For some sort of modern re-elaboration of the concept, see Pasinetti (1993; 2007): the labour theory of value should be understood within the perimeter of the 'natural system' which abstracts from any discussion on the specific institutional arrangements, included the dynamics of income distribution.
} 
In contrast to the Ricardian 'approximation', Marx acknowledges therefore the existence of a hiatus between production prices and labour values due to the condition regarding the uniformity of $r$ in the determination of prices, and his solution puts forth a "law of conservation of value" that operates at a macroeconomic level: the price of each commodity is allowed to fluctuate in response to shifts in distribution while these movements are presumed to compensate in the aggregate. To be more specific, Marx chooses the gross (annual) production $\mathbf{q}$ for its invariance postulate:

$$
\mathbf{q p}=\mathbf{q} \lambda
$$

That leads us to

$$
\mathbf{z}=\frac{\mathbf{q}}{\mathbf{q} \lambda}
$$

which means that the gross product per unit of embodied labour is the standard of measure for exchange value. It is no more any 'arbitrary' commodity vector $\mathbf{x}$ whose labour value matches price as Ricardo claimed, but only the vector representing total output at the end of the period. With this condition Marx can elaborate his theory of exploitation holding that gross profit is proportional to surplus-labour (surplus-value) appropriated by the owners of capital. If this were true, it would be proven that capitalist income comes through the exploitation of the labour class and that no disproportioned position can last as the rate of surplus-value adjusts itself together with $r$ when competition modifies production prices.

Unfortunately for Marx the devil is in the details. His mistake is notorious: the price equation is expressed as

$$
\mathbf{p}=(1+r) \mathbf{A} \lambda+\omega l
$$


which should respect the uniform rate of profit condition, but this is not granted because Marx considers advanced capital in its 'untransformed' form, i.e. computed at labour values instead of prices. ${ }^{11}$ A logically coherent determination of prices is provided by

$$
\mathbf{p}=(1+r) \mathbf{A p}+\omega l
$$

However, nothing ensures that equation (3.3) is equivalent to this last one. To be so, the total (aggregate) value of advanced capital should be equal to its total price, that is advanced capital should be invariant in the 'transformation process':

$$
\mathbf{q A} \lambda=\mathbf{q A p}
$$

Such equality is not true in general, being verified only in few special cases in which the Ricardian theory of value is also correct. Thus, Marxian labour theory of value is logically inconsistent, holding strictly true only under special circumstances just like that of Ricardo: it follows that, in general, we cannot trace back profit to unpaid labour time and the entire building of exploitation theory falls apart due to theoretical flaws in the analysis (Steedman, 1977).

Nevertheless, it seems like Marx had a grasp of the mistake his theory contained, so that, in his mind, the shortcomings of his conclusions were in fact just temporary proxies of the correct results he would have elaborated in later works had he not died in $1883 .{ }^{12}$ Indeed, he had in sight an 'average commodity' (composition-wise) to be set as numéraire that would have solved the controversy just like Ricardo had imagined half a century before. His great

\footnotetext{
${ }^{11}$ While Marx would include the workers' subsistence in advanced capital, we prefer to consider the post factum salary case for the sake of continuity with the previous pages.

${ }^{12}$ It may be useful to remember - as it is an often overlooked aspect in the debates concerning the 'transformation problem' - that only the first volume of Das Kapital was issued under Marx's supervision, the second and third ones (most of the discussion about the 'transformation' is found in the last volume) being revised and published by Friedrich Engels post mortem of the author.
} 
idea was to put the invariance condition on a macroeconomic level; his main error: the choice of the gross product as the invariant quantity.

\section{Keynes: from Pigou's «conundrum» to the labour-unit}

In his General Theory of Employment, Interest and Money ([1936]), Keynes' main aim is to understand and explain the levels of production and employment. To do so, he needs to clearly define them in order to compute their variations and eventually confront possible outcomes: in this sense, insofar his general scope is different, the study on growth he carries on at least partially overlaps with the inquiry on the unit of measure that had occupied many authors of the Classical School. ${ }^{13}$ Though it can be considered something of a detour from the rest of the book, the fourth chapter of the General Theory, meaningfully titled 'The Choice of Units', is indeed fully dedicated to the discussion of these issues.

En passant, it is interesting to note that there is no evidence of a chapter on the measure standard either in the first surviving drafts or in the early table of contents that Keynes had prepared (Keynes, 1973). However, a chapter named "the Units of Quantity" appears in the index of the fourth proof, incorporating critiques and suggestions from "a stiff week's supervision from $\mathrm{R}$ [ichard] $\mathrm{F}$ [erdinand] $\mathrm{K}[\mathrm{ahn}]$ " who is "a marvellous critic and suggester and improver" as we read in a letter from Keynes to Joan Robinson dated $29^{\text {th }}$ March, 1934.

\footnotetext{
${ }^{13}$ Keynes had actually tackled these subjects since the very beginning of his career: in 1909 he wrote a brief paper on the 'index numbers' that eventually earned him the Adam Smith Prize. Although he would not return on the matter for almost two decades, this juvenile text bears substantial previews of the fourth chapter of the G.Th. (Keynes, 1983, p. 49).
} 
The importance of Kahn is reiterated in two letters that Keynes sends him in September, during a period of complete revision of the work, where Keynes firstly explicates his inspiration:

I think I've solved the riddle of how to define income in some sort of a net sense - and it comes out very near to the money value of the Prof. [Pigou]'s national dividend (Keynes, 1973, p. 484).

And then also gives credit to the younger colleague for the new direction he is now following:

I am getting towards the end of the re-writing which you lead me into and will show you the new way for dealing with the net income in detail next term (Keynes, 1973, p. 485).

Keynes' problem is indeed quite similar to one Arthur Cecil Pigou had faced a few years before, i.e. measuring changes in current output independently of nominal variations and other irrelevant phenomena. He therefore moves from a criticism towards the latter's notion of "National Dividend" as presented in The Economics of Welfare (Pigou, [1932], part I, ch. III), a roughly similar variable to the more common aggregate income. The controversy arises from Pigou's attempt to compare inventories of heterogeneous commodities without having recourse to any kind of appraisal of their value, just observing the sheer composition of said inventories. Keynes understands that the 'materialist' interpretation provided by his elder colleague suffers from significant flaws: one of the obscure points of the Pigouvian position lies in the analysis of capital depreciation caused by machine wearing or ageing, as it may be impossible to take into account this loss of value and subsequently deduct it from the gross product if the capital stock is in fact materially unaltered: 
In order to arrive at the net national dividend, Professor Pigou deducts such obsolescence, etc., 'as may fairly be called "normal" [...]. But, since this deduction is not a deduction in terms of money, he is involved in assuming that there can be a change in physical quantity, although there has been no physical change; i.e. he is covertly introducing changes in value. ${ }^{14}$

Pigou himself, after extensive argumentation on the subject, ends up conceding that no such view can be sustained except in certain special cases, since two or more collections of different goods are reciprocally incommensurable unless their values are assessed on a common basis.

However, Keynes acknowledges the soundness of Pigou's focus on a net quantity, stressing that any analysis on growth should be centred on "the net addition, that is to say, to the resources of the community available for consumption or for retention as capital stock [during] the current period" (Keynes, [1936], p. 37). ${ }^{15}$ Great issues emerge when we take into consideration the accumulation of capital equipment, so that we are in need of a device to "evaluate new equipment against old when, owing to changes in technique, the two are not identical"; a suitable system of units should then be adopted in order to calculate the value of capital stocks, but Keynes deems any search in this sense to be hopeless because the matter appears as a "conundrum" with no solution, at the same time emphasising how the analysis must avoid any "quantitatively vague expression”.

Nonetheless, Keynes sketches a macroeconomic unit to be solely used as a proxy to evaluate changes in the aggregate output. This unit is the quantity (in hours) of employment or "labour-unit", through which we can measure variations of the current production resulting

\footnotetext{
${ }^{14}$ To be fair, not even Keynes' National Income provides a solution, dodging the question of capital stock subtraction from the gross output taking it fixed in the short period, the horizon limiting Keynesian theory in the fourth as well as in many other chapters of the book (with few notable exceptions).

${ }^{15}$ Italics added.
} 
from aggregate demand shifts, this possibility relying on the "general presumption" (so much for the formal precision!):

That the amount of employment associated with a given capital equipment will be a satisfactory index of the amount of resultant output; - the two being presumed to increase and decrease together, though not in a definite numerical proportion.

While the labour-unit is not strictly homogeneous due to differentials between unevenly skilled labour, it can be made so, Keynes stresses, counting an hour of 'special' labour twice as much as an ordinary one if it is remunerated at double ordinary rates, so that different efforts are esteemed according to their respective wages. Not interested in seeking for an absolute measure, Keynes just wants to compare different outputs in correspondence with a given capital equipment, that is with a fixed technique in a short-period horizon:

We shall measure changes in current output by reference to the number of hours of labour paid for (whether to satisfy consumers or to produce fresh capital equipment) on the existing capital equipment, hours of skilled labour being weighted in proportion to their remuneration.

Adopting the matrix algebra used in the previous chapters to translate Keynes' reasoning into formal terms, we can provide an equation for the net income:

$$
\mathbf{y}=\mathbf{q}(\mathbf{I}-\overline{\mathbf{A}})
$$

where the difference from equation (1.7) lies in the overbarred matrix $\overline{\mathbf{A}}$, capturing the fact that, as Keynes stresses, productive capacity is given in the short period.

Therefore, he hints that income dynamics should have an immediate reflection on the annual amount of labour hours, though no detailed explanations are offered. Anyway, the rationale is straightforward: as we encounter great difficulties in measuring net output, we 
may evaluate its volume in a roundabout way simply considering the hours of human effort that in any given technical environment are uniquely related to the quantity of commodities manufactured.

Quite in line with the relative scarcity of algebraic formulas in the whole book, Keynes presents his theory with only a couple of rather obscure equations, the most meaningful one shown as follows:

$$
\mathbf{y}=f(L)
$$

It immediately synthesises the description offered in the chapter: the relation of net output with employment may be expressed as a generic direct function, which indicates that both variables move jointly though these movements cannot be described in a more precise manner.

One of labour-unit's peculiar features is that it is thought and explicitly presented as a macroeconomic variable, in accordance with the macro-focus of the General Theory. In a sense, it could be said that Keynes, ever critical of Marxian economics (Skidelsky, 1992), catches the advice put forth by Marx and eventually changes the object of the problem from gross to net output and from total embodied labour to the hours of human effort directly expended upon the production of commodities. At the same time, the nature of the debt owed by Keynes towards the Classics should be examined with a critical eye: what is displayed is a purely macroeconomic theory that utterly refuses to evolve into a disaggregated analysis. If anything like a formal model could be built on the work of Keynes, it would turn out to be quite different to those of Smith, Ricardo and Marx as these are reconstructed in the previous sections. On the whole, Keynes and the Classics do not have a shared opinion on several fundamental theoretical concepts: to name but a couple, in the framework of the General 
Theory prices are determined by demand and supply interactions rather than by real cost of production and wages are supposed to be equal to the marginal productivity of labour.

Anyhow, as far as we limit ourselves to the discussion on the standard of measure the similarities cannot be denied; for all that it can only operate as a proxy, mainly due to a missing deeper meditation (possibly on account of a perceived lack of essentiality of the issue in Keynes' opinion), the labour-unit constitutes yet another step toward a coherent solution of the problem of the choice of units. 


\section{Sraffa: beyond the classical impasse}

Piero Sraffa's Production of Commodities by means of Commodities (1960) has brought back to light the approach of Classical economists to elaborate a modern arrangement of XIX century theory, at the same time serving as a radical critique to the marginalist mainstream.

The Italian scholar represents the basic elements of an economy in a long period position as a system of simultaneous equations, each of them standing for the working of an industry as a whole; wage and profit rates are uniform on account of free competition conditions:

$$
\mathbf{p}=(1+r) \mathbf{A p}+l \omega
$$

The level of production is normalised provided that we make the annual labour equal to 1 , that is:

$$
L=\mathbf{q} l=1
$$

Now let's define net product as:

$$
\mathbf{y}=\mathbf{q}(\mathbf{I}-\mathbf{A})
$$

Sraffa then points out that we can choose the price of net product as the unit of measure, so that every quantity can be interpreted as a share of the total output. The equation for the measure standard therefore becomes:

$$
\mathbf{y p}=1
$$

From this last equation it is clear that a (not so) surprising continuity exists from the Classics to Sraffa: where Ricardo chooses an arbitrary vector of commodities and Marx opts for the gross product $\mathbf{q}$, Sraffa employs the net product, whose price serves as standard. But it is also 
noteworthy that Sraffa points in the direction of a net quantity just like Keynes did in the fourth chapter of his General Theory a few years before, although there is no evidence of a mutual influence between the two colleagues and friends on this point. As stated above, there is a good chance that it was Richard Kahn, "the éminence verte who only got acknowledged in other author's footnotes" (Samuelson, 1994), to lead Keynes towards a net product solution. On the other side, it might be of some interest to note that we almost have no reports of Sraffa's comments on the main themes of the General Theory, not even in his unpublished drafts archived at the Trinity College library. We only indirectly know that Sraffa's reception of the General Theory was, at best, tepid: Richard Goodwin recalls that, having repeatedly asked him for a comment on Keynes' magnum opus, he got in response a blunt "I did not like the book" (Velupillai, 2008).

As a matter of fact, the fields on which the two focused were slightly different: while Keynes studied the possibility of less-than-full employment equilibria, the Italian gave himself a 'Ricardian' task, that is to explain the schemes of distribution of the surplus rather than the way it is produced, taking the output quantities as given. It may turn out that he found himself quite dissatisfied with Keynes' argument and avoided public intervention not to be harsh (as it was his usual custom in criticising colleagues) with a close friend; or it may as well result that his silence was compliant with Ludwig Wittgenstein's (another great friend of his) most famous principle "about what one cannot speak, one must remain silent", thus refusing to pronounce himself on a matter that in his opinion could be too complex to be reduced into a model.

Whatever the case, within the boundaries of their respective theories the two scholars followed a similar path in the search for a unit of measure based on net output; but once again, while Keynes' capital deduction is ambiguous and approximate, Sraffa rigorously 
subtracts the commodities used up as means of production to give a clear definition of net product as a collection of goods to be either accumulated or distributed for consumption.

With an orthodox Sraffian stance, Steedman (1977) highlights how the determination of production prices in Production of Commodities only requires the prior knowledge of technical conditions and a distribution variable, the second one being determined along with prices. Indeed, we need to exogenously fix $\omega$ or $r$ to close the system reducing the variables to be determined to the $n-1$ relative prices and the endogenous distribution variable. While the Classics consider the wage permanently stuck at the subsistence level because of either the Malthusian principle or the asymmetric bargaining power of workers and capitalists, Sraffa is willing to take the rate of profit as externally determined by the influence of the money market.

Then, a complete representation of the Sraffian analysis runs as follows:

$$
\begin{aligned}
& \mathbf{p}=(1+r) \mathbf{A p}+\omega l \\
& \mathbf{y p}=1 \\
& r=\bar{r}
\end{aligned}
$$

Equations (1.1), (5.3) and (5.4) provide a logically coherent determination of relative prices and distribution patterns without having recourse to labour embodiment or command. Hence, according to Neo-Ricardian scholars any Classical-Marxian discussion concerning labour values is to be considered superfluous, the 'evidence of class conflict' (Garegnani, 1984, 2018) being underscored by the well-known wage-profit equation, $\omega=1-\frac{r}{R}$, that becomes 
linear under specific circumstances, ${ }^{16}$ and the existence of exploitation being explained by the sheer fact that workers receive less than the whole product (Garegnani, 1984; see also Petri, 1989). Even though individual positions among the followers of Sraffa are marked by considerable differences, the idea that labour value plays no relevant role in the working of the economy enjoys fairly broad agreement inside the Neo-Ricardian school (Petri, 2015); if anything, labour values can be derived from production prices instead of being their theoretical substrate, with a full reversal of the Classical-Marxian perspective.

\section{A general theory of the standard of measure: net labour productivity}

A conflicting view is supported by a few authors, who reads in a passage of Sraffa's book a remarkable hint to be recognised and explicated. According to them, Production of Commodities' 'oblique' suggestion is disguised in two early paragraphs whose declared purpose is the preliminary definition of variables and units to be employed in the continuation of the book. It is the opinion of Bellofiore (2008), Gattei \& Gozzi (2009) and Perri (2010) that the double normalization of $\S 10$ and $\S 12$ leads to a substantial anticipation of the so called 'New Interpretation' of the transformation problem set forth by Duménil (1980) and Foley (1982) several years later. Indeed, (5.1) and (5.3) suggest that the price of the net product should be equal to the annual labour, that is:

$$
\mathbf{y p}=\mathbf{q} l
$$

This is equivalent to putting the value-invariance condition on a macroeconomic level but, differently to Marx, the invariant quantity is now the net output and its counterpart the direct

\footnotetext{
${ }^{16}$ Namely, when all prices and quantities are expressed in terms of the 'Standard commodity'.
} 
or 'living' labour, so that the controversial treatment of advanced capital as embodied ('dead') labour is totally bypassed. This equality gives shape to the idea that the price of the net product is expression of the annual labour expended in the production of commodities (Foley, 1982: 37-8). Once again, Keynes seems to have disclosed in advance this opportunity, though his 'general presumption' on the labour-unit function lacks the formal precision that the matter would require and that he was not interested or keen enough to provide.

As a consequence, equation (6.1) offers a suitable unit of measure in the form of the net output per hour of labour, or net labour productivity of the economy, that is:

$$
\frac{\mathbf{y p}}{\mathbf{q} l}=1
$$

This numerary condition allows for a proper representation of the economic system, overcoming the logical obstacles the labour theory of value had encountered among the Classics. The relative price structure of the economy is then coherently determined for any distribution pattern:

$$
\begin{aligned}
& \mathbf{p}=(1+r) \mathbf{A p}+\omega l \\
& \frac{\mathbf{y p}}{\mathbf{q} l}=1 \\
& r=\bar{r}
\end{aligned}
$$

This latter system is expression of a true 'general theory of the numéraire' built upon the implicit solution reconstructed from the hidden clues allegedly scattered by Sraffa, correctly computing exchange values and at the same time preserving those conclusions that analytical flaws within Classical labour theories of value had jeopardised. Accordingly, the real variable 
of interest is net labour productivity that, within the perimeter of this approach, distinguish itself as the most appropriate standard of value to analyse the dynamics of the economy: on the one hand it works as a suitable unit of count to logically determine exchange ratios, on the other it helps bringing to light the fact that only (living) labour is the source of value. As a purely artificial device to solve an almost metaphysical quest for the supposed substance of value, postulating the existence of this invariant unit allows to exactly measure value and at the same time to show the real nature of economic relations in the capitalist mode of production.

While the effective Sraffian paternity of this approach is questionable, and for all that its ideological premises are made object of debate, it could arguably represent a useful empirical unit in heterodox works, especially in Pasinettian models (as the third Italian edition of prof. Pasinetti Lezioni di Teoria della Produzione suggests to employ this unit (Pasinetti, 1989, p. 172)). Although it obviously does not represent an algebraic proof, it is no less than the most famous volume in the history of economic analysis to clearly state in its opening that "the annual labour of every nation is the fund which originally supplies it with all the necessaries and conveniences of life which it annually consumes" (Smith, [1776]). 


\section{Bibliography}

Bellofiore, R. (2008) 'Sraffa after Marx: An Open Issue', in Chiodi, G. \& Ditta, L. (eds.) Sraffa or an Alternative Economics, Basingstoke: Palgrave Macmillan.

DuMÉNIL, G. (1980) De la valeur aux prix de prodution, Paris: Economica.

FolEy, D. K. (1982) 'The Value of Money, the Value of Labor Power, and the Marxian Transformation Problem', Review of Radical Political Economics, 14 (2): 37-46.

Garegnani, P. (1984) 'Value and distribution in the classical economists and Marx', Oxford Economic Papers, 36 (2), 291-325.

Garegnani, P. (2018) 'On the Labour Theory of Value in Marx and in the Marxist Tradition', Review of Political Economy, 30 (4), 1-25.

GATteI, G. \& GozzI, G. (2009) 'Sraffa come "classico": un esercizio congetturale', Working Papers DSE Università di Bologna.

KeYnes, J. M. (1973) The Collected Writings of John Maynard Keynes, Vol. XIII, The General Theory and After: Part I. Preparation (E. Johnson \& D. Moggridge, Eds.), London: Royal Economic Society.

KeYnes, J. M. (1983) The Collected Writings of John Maynard Keynes, Vol. XI, Economic Articles and Correspondence: Academic (E. Johnson \& D. Moggridge, Eds.), London: Royal Economic Society.

KeYneS, J. M. (2009) [1936] General Theory of Employment, Interest and Money, New York: Classic Books America.

KURZ, H. (2006) "The agents of production are the commodities themselves: on the classical theory of production, distribution and value", Structural Change and Economic Dynamics, $17,1-26$.

MARX, K. (1990) [1867] Capital, vol. I, London: Penguin Books.

PASINETTI, L. L. (1989) [1977] Lezioni di teoria della produzione, Bologna: il Mulino.

PasinetTi, L. L. (1993) Structural Economic Dynamics - A theory of the economic consequences of human learning, Cambridge: University Press.

PASINETTI, L. L. (2007) Keynes and the Cambridge Keynesians: a Revolution in Economics to be Accomplished, Cambridge: University Press. 
PERRI, S. (2010) "From the "Loaf of Bread" to "Commodity Fetishism": a "New Interpretation” of the Marx-Sraffa connection', History of Economic Ideas, 18, 55-81.

Petri, F. (1989) Teorie del valore e della distribuzione: un confronto tra classici e neoclassici, Roma: NIS.

PETRI, F. (2015) 'On Some Modern Reformulations of the Labour Theory of Value', Contributions to Political Economy, 34 (1), 77-104.

PetTy, W. (1690) Political Arithmetick, London: Clavel and Mortlock.

PigOU, A. C. (2013) [1932] The Economics of Welfare, Basingstoke: Palgrave Macmillan.

RICARDO, D. (1815) 'An essay on the influence of a low price of corn on the profits of stock', in Sraffa, P. (ed.) (1951) The Works and Correspondence of David Ricardo, IV, Cambridge: University Press.

RicARDO, D. (1821) 'On the Principles of Political Economy and Taxation', in Sraffa, P. (ed.) (1951) The Works and Correspondence of David Ricardo, I, Cambridge: University Press.

SAMUELSON, P. A. (1994) 'Richard Kahn: His welfare economics and lifetime achievement', Cambridge Journal of Economics, 18 (1), 55-72.

SECCARECCIA, M. (1982) 'Keynes, Sraffa et l'économie classique: le problème de la mesure de la valeur', L'Actualité économique, 58 (1-2), 115-51.

SkIDELSKY, R. J. A. (1992) John Maynard Keynes Vol. 2: The Economist as Saviour, London: Macmillan.

Smith, A. (1977) [1776] An Inquiry into the Nature and Causes of the Wealth of Nations, Chicago: University of Chicago Press.

SRAFFA, P. (1951) 'Introduction', in Sraffa, P. (ed.) (1951) The Works and Correspondence of David Ricardo, 1, Cambridge: University Press.

SRAFFA, P. (1960) Production of commodities by means of commodities: prelude to a critique of economic theory, Cambridge: University Press.

STEEDMAN, I. (1977) Marx after Sraffa, London: New Left Books.

STIGLER, G. (1958) 'Ricardo and the 93\% Labor Theory of Value', American Economic Review, 48: 357-67.

Velupillai, V. K. (2008) 'Sraffa's Economics in Non-Classical Mathematical Models', in Chiodi, G. \& Ditta, L. (eds.) Sraffa or an Alternative Economics, Basingstoke: Palgrave Macmillan. 


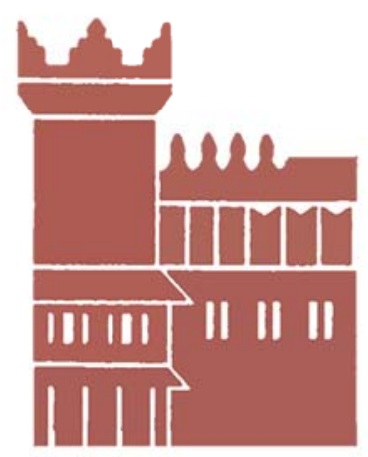

Alma Mater Studiorum - Università di Bologna DEPARTMENT OF ECONOMICS

Strada Maggiore 45

40125 Bologna - Italy

Tel. +39051 2092604

Fax +390512092664

http://www.dse.unibo.it 